\title{
Estrogen receptor $\beta$ promoter methylation: a potential indicator of malignant changes in breast cancer
}

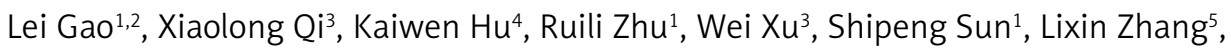
Ximing Yang ${ }^{6}$, Baojin Hua ${ }^{7}$, Guijian Liu $^{1}$

\author{
'Laboratory Department, GuangAn'men Hospital, China Academy of Chinese Medical \\ Sciences, Beijing, China \\ 2Department of Oncology, Beijing Hospital of Traditional Chinese Medicine, \\ Capital University of Medical Sciences, Beijing, China \\ ${ }^{3}$ Department of General Surgery, Nanfang Hospital, Southern Medical University, \\ Guangzhou, China \\ ${ }^{4}$ Department of Oncology, Dongfang Hospital Affiliated to Beijing University \\ of Chinese Medicine, Beijing, China \\ ${ }^{5}$ Anyang Cancer Hospital, Anyang, China \\ ${ }^{6}$ Laboratory Department, Dongzhimen Hospital Affiliated to Beijing University \\ of Chinese Medicine, Beijing, China \\ 'Department of Oncology, GuangAn'men Hospital, China Academy of Chinese Medical \\ Sciences, Beijing, China
}

Submitted: 18 December 2013

Accepted: 12 February 2014

Arch Med Sci 2016; 12, 1: 129-136

DOI: $10.5114 /$ aoms.2016.57588

Copyright $\odot 2016$ Termedia \& Banach

\begin{abstract}
Introduction: Estrogen receptor $\beta$ (ER $\beta$ ) always lacks expression in estrogen-dependent tumors, which may result from gene inactivation by methylation. In this study, we aimed to determine whether aberrant methylation of the ER $\beta$ promoter is associated with decreased ER $\beta$ gene expression in breast cancer.
\end{abstract}

Material and methods: ER $\beta$ methylation status was determined for 132 pairs of breast cancer and adjacent normal tissues via the MethyLight method. Additionally, mRNA relative expression was quantified by real-time polymerase chain reaction (RT-PCR) to determine whether aberrant methylation had a negative correlation with expression. The correlation of ER $\beta$ promoter methylation and clinical parameters is also discussed.

Results: Methylation was observed in 96 (72.7\%) breast cancer samples, and the median percentage of fully methylated reference (PMR) among methylated tissues was 0.83 . Meanwhile, 94 (71.2\%) adjacent normal tissues were methylated and the median PMR was 0.48 . Compared to adjacent normal tissues, the methylation level of breast cancer was significantly higher $(p<0.001)$ and mRNA expression was much lower $(p<0.001)$. There was a significant correlation between ER $\beta$ methylation and mRNA expression in adjacent normal breast tissues $(p=0.004)$. In addition, the methylation rate of cancer tissues whose maximum diameter $<3 \mathrm{~cm}$ was significantly higher than those $>3 \mathrm{~cm}(p=0.025)$.

Conclusions: ER $\beta$ promoter methylation level varies between cancerous and adjacent normal breast tissues. There was significant downregulation of ER $\beta$ methylation expression in pre-cancerous stages of breast cancer. Therefore, demethylation drugs may offer a potential strategy for preventing the development of pre-cancerous cells.

Key words: breast cancer, estrogen receptor $\beta$, methylation, percentage of fully methylated reference.

\author{
Corresponding author: \\ Guijian Liu \\ Laboratory Department \\ GuangAn'men Hospital \\ China Academy of Chinese \\ Medical Sciences \\ No. 5 Beixian'ge Road \\ Xicheng District \\ 100053 Beijing, China \\ Phone: +86-10-88001006 \\ E-mail: \\ liuguijian@hotmail.com
}




\section{Introduction}

Estrogen receptor $\beta(E R \beta)$ has been recognized as a member of the nuclear receptor superfamily, which has also included the traditional estrogen receptor $\alpha$ since 1996 [1]. These estrogen receptors have common structural features but play different biological roles that are mediated via their DNA-binding domains, which interact with specific DNA elements, such as the estrogen-response element, to activate downstream target genes [2]. ER $\beta$ has, unlike estrogen receptor alpha, different functions and a wider distribution among a variety of tissues, including breast, colon, esophagus, stomach, brain, lung, prostate, testis, pancreas and blood vessels [3]. In breast tissues, ER $\beta$ is expressed in luminal epithelium, myoepithelium, fibroblasts and lymphocytes in stromal cells [4]. The ER $\beta$ expression level is down-regulated in malignant breast tissue [5]. Although the final conclusion is still inconsistent about the relationship of ER $\beta$ expression level and prognosis as well as treatment response, ER $\beta$ has been accepted as a tumor suppressor gradually [6]. Recent research strongly supported that loss of ER $\beta$ could be one of the key elements leading to breast epithelial cell malignancy. It suggested that ER $\beta$ has a significant role in inhibition of invasion, stimulation of apoptosis, and prevention of oncogenic transformation in rapid differentiating prostatic epithelial cells [7].

DNA epigenetic alternation including gene-specific hypermethylation and hypomethylation has a significant influence on neoplastic transformation [5, 7]. Gene silencing due to DNA hypermethylation of $\mathrm{CpG}$ islands in the promoter regions is a common mechanism of gene regulation in breast carcinogenesis [8, 9]. Aberrant DNA methylation is regarded as one of the most common molecular abnormalities in breast cancer, and hypermethylation of $\mathrm{CpG}$ islands results in the loss of expression of some crucial genes [9]. Studies in vitro show that $E R \beta$ methylation probably participates in the epigenetic regulation of ER $\beta$ expression [10-15], and methylation of the ER $\beta$ promoter is an early event in malignant transformation of breast tissue [15]. Different methylation models in cancer cell lines and breast cancer tissues have been classified for two ER $\beta$ promoters, exon OK and $O N$, which could generate different ER $\beta$ isoforms with diverse splicing sites [10]. However, few studies of ER $\beta$ methylation have been conducted on paired cancerous and normal tissues from a single patient.

In this study, we aimed to investigate the relationship and consistency between promoter methylation status and ER $\beta$ expression levels, along with clinical parameters, of paired cancerous and normal tissues in breast cancer patients.

\section{Material and methods}

\section{Patients and samples}

The study protocol was approved by the Institutional Review Board and all participants signed a written consent form. Tissues of 132 breast cancer objects were collected from September 2010 to October 2011 at the Anyang Cancer Hospital in the Henan province of China. All participants were Chinese Han women, mean age $50.91 \pm 9.88$ years, and baseline characteristics are shown in Table I. None of them had received preoperative hormonal therapy. Cancerous and adjacent normal tissues were collected from each patient during surgery. Normal breast tissues were obtained at least $1 \mathrm{~cm}$ distant to the edge of cancerous breast tissue. Subsamples of tissues were removed prior to DNA extraction for conventional fixed, embedded and $\mathrm{H}+\mathrm{E}$ staining. Histopathological categories including benign and malignant characterizations were verified by two experienced pathologists. Each tissue was divided into two parts, and one was placed in RNA Stabilization Reagent (Qiagen, Valencia, CA), while the other was stored at $-80^{\circ} \mathrm{C}$ until extraction.

\section{DNA extraction and bisulfite modification}

Genomic DNA was extracted from tissues by the standard method of proteinase $K$ digestion and phenol-chloroform extraction [16]. In brief, fresh tissues were diced and DNA was extracted after the tissue pieces were digested overnight. The purity and concentration of extracted DNA were determined from its optical density by use of a Nano-Drop spectrophotometer (NanoDrop Technologies, Wilmington, Delaware, USA). Sodium bisulfite conversion of approximately $800 \mathrm{ng}$ of extracted genomic DNA was performed for the EZ DNA Methylation Gold Kit (Zymo Research, Orange, (A, USA) and diluted to a final concentration of $25 \mathrm{ng} / \mu \mathrm{l}$.

\section{PCR and Sanger sequencing for promoter OK}

After sodium bisulfite conversion, genomic DNA methylation status of promoter OK was verified according to PCR-based sequencing on 20 pairs of cancerous and adjacent normal tissues. Hot Start Taq DNA polymerase mixture (Qiagen, Valencia, CA) was used to amplify the promoter OK fragment (295 bp) on bisulfite converted DNA. Primers for promoter OK are listed in Table II. PCR products were purified using a PCR clean-up gel extraction column (Macherey-Nagel $\mathrm{GmbH}$ \& Co, Düren, Germany). The sequences were determined using a capillary sequencer ( $A B I$ Prism 3100). 


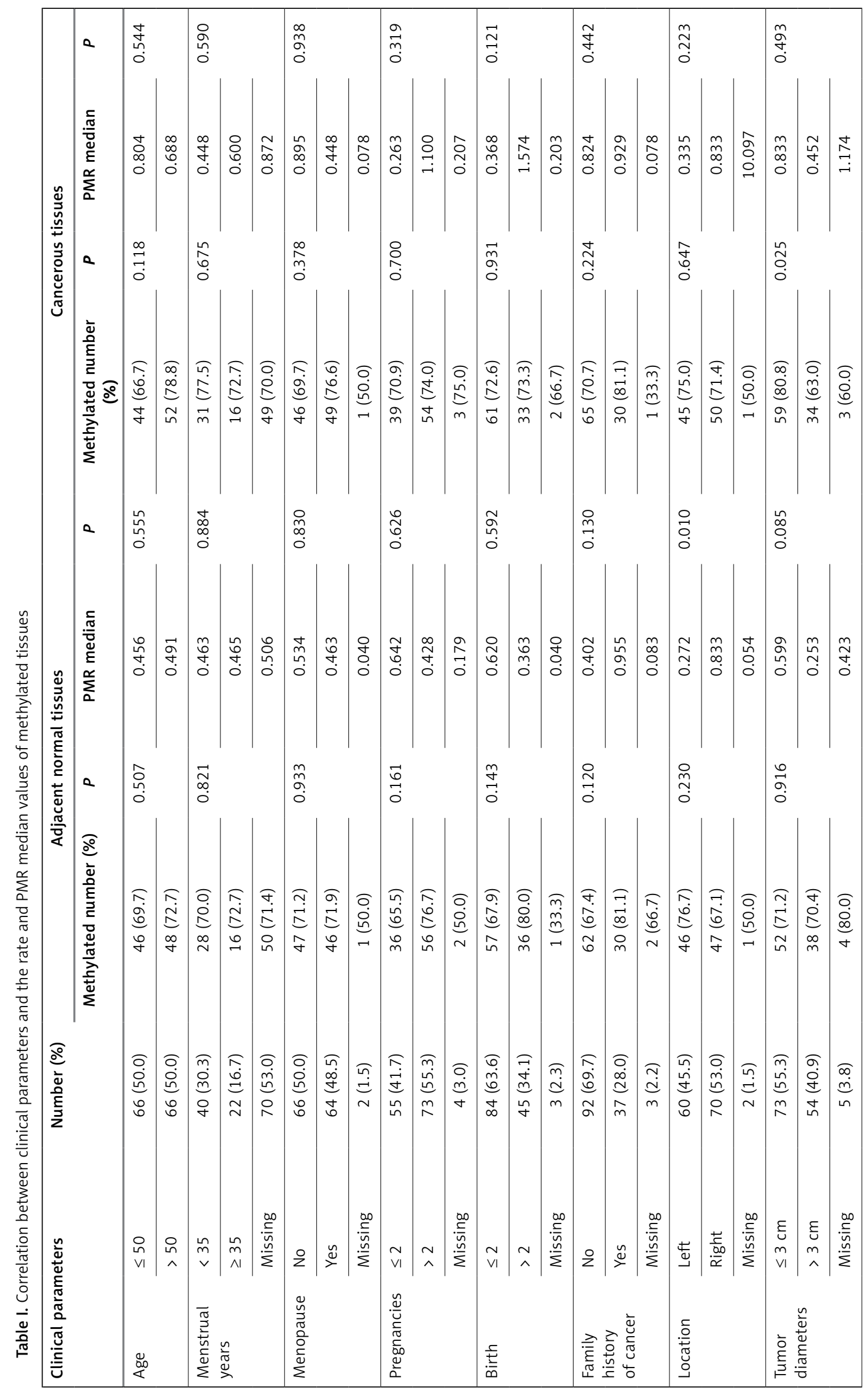




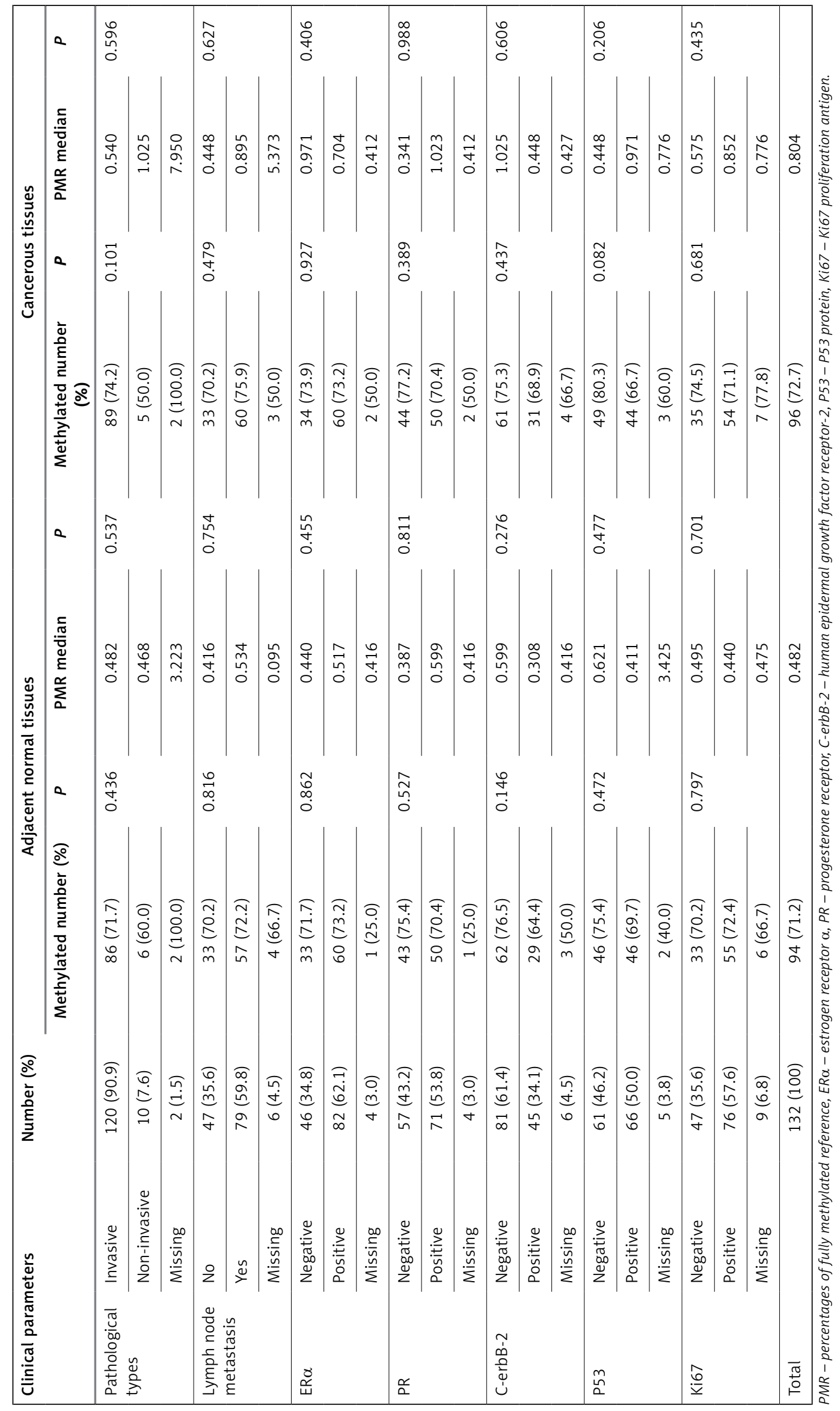




\section{Methylation assay for promoter $\mathrm{ON}$}

Methylation analysis of promoter ON was performed by the MethyLight method [17]. Three sets of primers and probes designed specifically for bisulfite-converted DNA were used, and an ACTB set was used to normalize for input DNA. The sequences of primers and probes are shown in Table II. Specificity of the reactions for methylated DNA were confirmed separately by a control human genomic DNA which had been treated with DNA methyltransferase Sssl (New England Biolabs, Beverly, MA). The percentage of fully methylated molecules at a specific locus was calculated by dividing the promoter $O N$ : $A C T B$ ratio of a sample by the promoter ON: ACTB ratio of Sssl-treated control DNA and multiplying by 100 . Percentages of fully methylated reference (PMR) values were used to quantity the methylation level of each sample. PMR >0 means that the measurement and gene are methylation positive.

\section{RNA extraction and real-time RT-PCR}

Total RNA was isolated from tissues that were stored in RNA stabilization reagent (Qiagen, Valencia, CA) using TRIzol reagent (Invitrogen, Carlsbad, CA) after a quick liquid nitrogen grind. The quality and quantity of RNA were determined from its optical density in an ethidium bromide-stained $1 \%$ agarose gel, and $2 \mu \mathrm{g}$ of RNA was subsequently used to generate CDNA with the M-MLV reverse transcription kit (Invitrogen, Carlsbad, CA). Real-time quantitative PCR was performed with a LightCycler 480 System (Roche Diagnostics GmbH, Mannheim, Germany). The LightCycler 480 SYBR Green I Master (Roche Diagnostics $\mathrm{GmbH}$, Mannheim, Germany) assay was used for total ER $\beta$ amplification and GAPDH was used as a reference gene. The $20 \mu \mathrm{l}$ reaction system contained $10 \mu \mathrm{l}$ of SybGreen mix, $10 \mathrm{pmol}$ of each primer, and 50-100 ng of cDNA template. The primers used are listed in Table II. Relative expression levels of total ER $\beta$ were calculated by

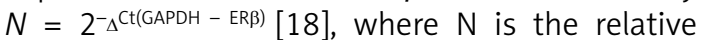
quantity of mRNA expression.

\section{Statistical analysis}

Non-parametric statistics were used because the distribution of PMR and $N$ value were not normal. The Spearman correlation coefficient and paired rank sum test were adopted for analysis of methylation and expression levels in cancerous and adjacent normal tissues. Pearson $\chi^{2}$ and Wilcoxon rank sum tests were used to analyze the relationship between methylation levels and clinical parameters. All statistical analyses were conducted using SPSS 17.0 software, and $p<0.05$ was considered as statistically significant.

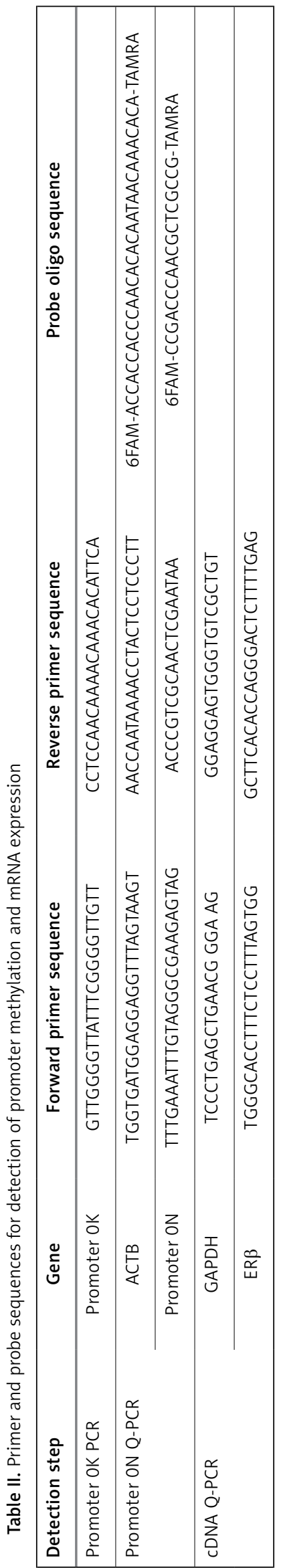




\section{Results}

\section{Histopathology}

All cancerous tissue samples were correctly classified and benign samples included normal and proliferative breast cells. All procedures were confirmed by two experienced pathologists independently.

\section{Promoter OK methylation}

Twenty participants were selected by a random number table (accounting for $15 \%$ of all patients), and their paired cancerous and adjacent normal tissues were used for promoter OK methylation assay. No methylation was observed from the sequencing chart.

\section{Promoter $0 \mathrm{~N}$ methylation and mRNA expression}

The DNA MethyLight Q-PCR assay was conducted on 132 pairs of breast cancer and adja- cent normal tissues. Methylation positive breast cancer tissues $(n=96)$ had a median PMR value of 0.83 , while adjacent normal breast tissues $(n=94)$ which were methylation positive had a median PMR value of $0.48(p<0.001)$ (Figure $1 \mathrm{~A})$. The median $m R N A$ relative expression level value $\left(N^{*} 1000\right)$ of cancerous tissues was 0.18 compared with 7.30 of adjacent normal tissues $(p<0.001)$ (Figure 1 B). However, several cases presented an opposite change of PMR or mRNA levels (e.g. cancer tissue with a high mRNA level or low methylation).

One hundred and eleven pairs of breast tissues were included for the analysis due to the lack of 21 samples for mRNA expression level. From the results, there was no significant correlation between promoter ON methylation PMR and mRNA expression levels in the breast cancer group $(p=0.899)$, but there was a significant correlation in normal breast tissue ( $p=0.004)$.
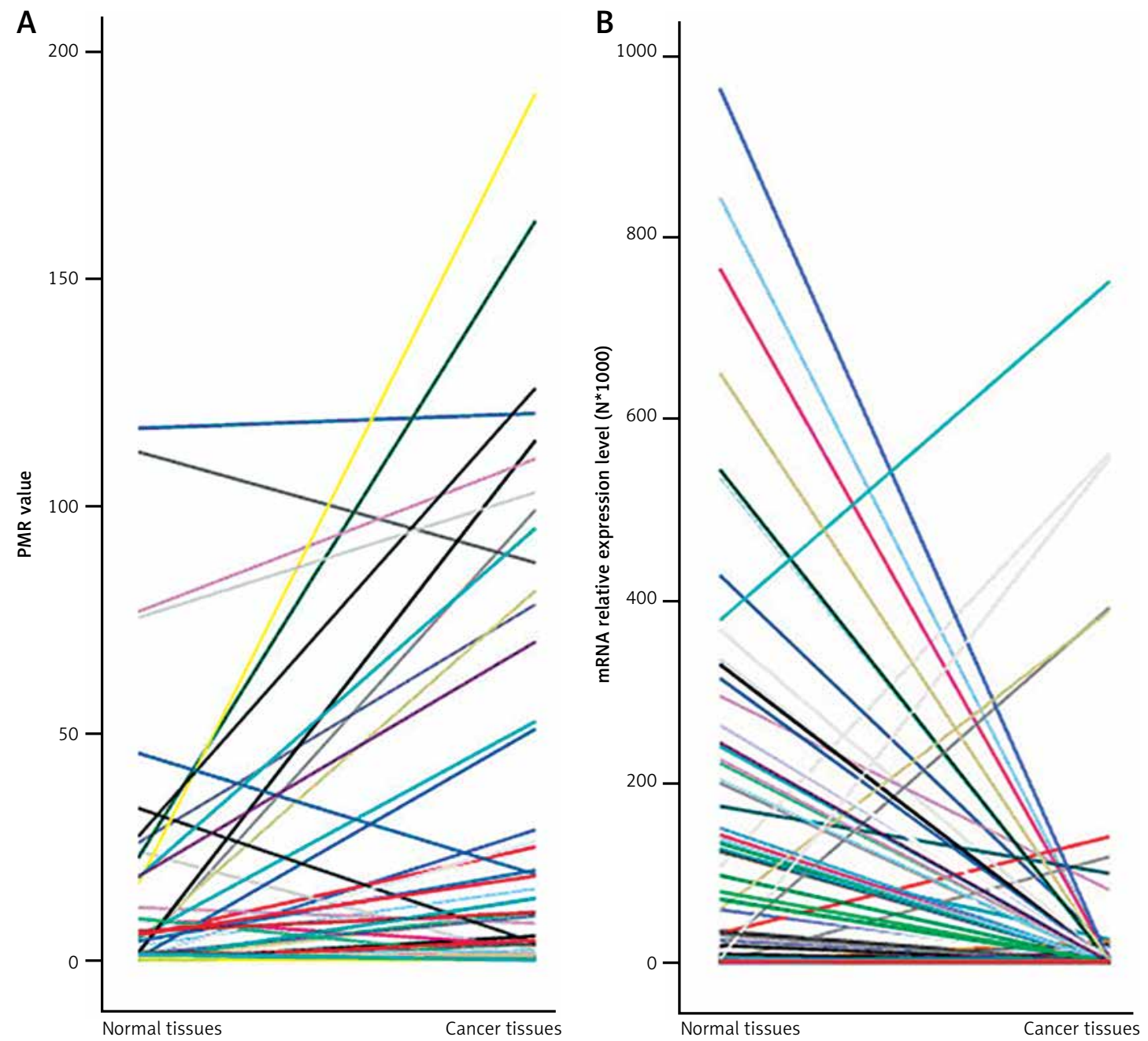

Figure 1. Estrogen receptor beta methylation PMR values and mRNA relative expression levels. Each line stands for a participant. The start point (adjacent normal breast tissues) and end point (breast cancerous tissues) mean PMR value $(A)$ or mRNA relative expression levels $\left(N^{*} 1000\right)(B)$

$P M R$ - percentages of fully methylated reference. 


\section{Methylation and clinical parameters}

The rate and PMR median values of methylated tissues were calculated for associations with clinical parameters. The rate of ER $\beta$ methylation in cancer tissues with maximum diameters $<3 \mathrm{~cm}$ was significantly higher than those $>3 \mathrm{~cm}$ $(p=0.025)$. However, the PMR median values in both groups showed no statistical significance $(p=0.493)$. Also, the PMR of left breast cancer was relatively higher than the other side $(p<0.01)$, although the rate of methylation did show significance $(p>0.01)$.

\section{Discussion}

The ER $\beta$ promoter region has been cloned with an increased CG content [19], and further investigation showed 2 exons ( $\mathrm{ON}$ and $\mathrm{OK}$ ) existing in the ER $\beta$ promoter region [11]. The methylation pattern for exon $0 \mathrm{~N}$ differs in cancerous and normal breast tissues, in contrast to exon $0 \mathrm{~K}[10,15]$. A previous study verified that promoter $0 \mathrm{~K}$ did not methylate either in benign or malignant breast cells [10]. As a scattered CG dinucleotide distribution in the promoter OK, a PCR-based sequencing method was designed to depict the GC methylation status in the promoter $\mathrm{OK}$ region. After scanning, no methylation occurred in any of the 20 paired tissues in our study, and this was consistent with the former results [10]. Promoter $\mathrm{OK}$ and $\mathrm{ON}$ could transcribe different mRNA isoforms which diverge in their 5'-untranslated regions, and the isoform change in carcinogenesis might be caused by a different methylation pattern [20]. We quantified promoter ON methylation to evaluate the DNA methylation status of CPG islands with the MethyLight method, and used established probes and primers in the promoter $0 \mathrm{~N}$ region $[21,22]$. Widschwendter et al. demonstrated that $79 \%$ of breast cancer tissues were methylated with a median PMR value of 0.1 [22]. In our study, similar results with an ER $\beta$ methylation rate for breast cancer tissue of $72.3 \%$ and a median PMR value 0.17 were proved, which confirmed the reliability for the further analyses.

Recent studies indicated that ER $\beta$ mRNA expression levels were down-regulated by promoter methylation, and re-expression occurred with the addition of DNA methyltransferase inhibitors [10, 12]. Transcriptional silencing of $E R \beta$ is necessary for cancer progression in breast cancer and other hormone-sensitive cancers [13]. Promoter methylation in cancerous and pre-cancerous tissues results in transcriptional silencing of ER $\beta$, whereas no methylation occurs in normal breast tissue [14, 15]. Therefore, ER $\beta$ is increasingly believed to act as a tumor suppressor gene [12]. Rody et al. speculated that methylation of the ER $\beta$ promoter is an uncommon focal event, based on the absence of methylation in benign breast tissue from breast cancer patients [15]. However, we found that there was no difference in methylation rate between cancerous and adjacent normal breast tissues. This inconsistency could have resulted from different methods, patient sources, or differences in sample size. We can deduce that the surrounding tissue of breast cancer differs from normal breast tissues without ER $\beta$ promoter methylation [23]. Therefore, adjacent normal breast tissues may be in a pre-cancer stage and ER $\beta$ methylation may be an early indicator of pre-malignant changes.

Compared with adjacent normal tissue, a significant decline of ER $\beta$ expression in breast cancer tissue was proved in our study (Figure $1 \mathrm{~B}$ ), which was also reported previously $[24,25]$. According to the correlation analysis, there was a relationship between methylation level and mRNA expression in adjacent normal breast tissue. The possible explanations might be as follows: first, compared with normal breast tissues, cancerous tissues included more complicated cell types, not only cancer cells in different differentiation stages but also normal duct cells, glandular cells and stromal cells. The ER $\beta$ expression level varies significantly in different cells. Second, the extracted tissues were not micro-dissected, which may result in an uncontrolled proportion of malignant cells. As a result, the kind of relationship in cancerous tissues might be not obvious. Finally, DNA methylation occurs in early carcinogenesis [26, 27]; therefore, the push power from methylation might decline during the tumor progression due to multiple uncontrollable factors. In our study, the rate of promoter $\mathrm{ON}$ methylation in cancer tissues with maximum diameter $<3 \mathrm{~cm}$ was significantly higher than those $>3 \mathrm{~cm}$. It may result from the smaller tumors always being in the early stage of tumor development. Unlike DNA genetics, epigenetic changes are reversible and ER $\beta$ re-expression is evident in the presence of DNA methyltransferase inhibitors [10, 12, 28]. Therefore, demethylation drugs may be a potential means for altering the development of pre-cancerous cells.

In conclusion, a relationship between methylation level and mRNA expression in adjacent normal breast tissue was observed in the study. Also, the level of ER $\beta$ promoter methylation varied between breast cancerous and adjacent normal tissues. The reversion of ER $\beta$ methylation in pre-cancerous stages may suggest a significant role in the prevention of breast cancer.

\section{Acknowledgments}

Lei Gao and Xiaolong Qi - these authors contributed equally to this work.

This work was supported by a grant from the GuangAn'men Hospital, China Academy of Chinese Medical Sciences (Number: 2011S244). We 
thank Richard J. Santen for his professional instructions for preparation of this manuscript.

\section{Conflict of interest}

The authors declare no conflict of interest.

\section{References}

1. Mosselman S, Polman J, Dijkema R. ER beta: identification and characterization of a novel human estrogen receptor. FEBS Lett 1996; 392: 49-53.

2. Ramsey TL, Risinger KE, Jernigan SC, Mattingly KA, Klinge CM. Estrogen receptor beta isoforms exhibit differences in ligand-activated transcriptional activity in an estrogen response element sequence-dependent manner. Endocrinology 2004; 145: 149-60.

3. Younes M, Honma N. Estrogen receptor beta. Arch Pathol Lab Med 2011; 135: 63-6.

4. Speirs V, Skliris GP, Burdall SE, Carder PJ. Distinct expression patterns of ER alpha and ER beta in normal human mammary gland. J Clin Pathol 2002; 55: 371-4.

5. Shaaban AM, O'Neill PA, Davies MP, et al. Declining estrogen receptor-beta expression defines malignant progression of human breast neoplasia. Am I Surg Pathol 2003; 27: 1502-12.

6. Leung YK, Lee MT, Lam HM, Tarapore P, Ho SM. Estrogen receptor-beta and breast cancer: translating biology into clinical practice. Steroids 2012; 77: 727-37.

7. Cheng J, Lee EJ, Madison LD, Lazennec G. Expression of estrogen receptor beta in prostate carcinoma cells inhibits invasion and proliferation and triggers apoptosis. FEBS Lett 2004; 566: 169-72.

8. Rivenbark AG, Coleman WB. Field cancerization in mammary carcinogenesis - implications for prevention and treatment of breast cancer. Exp Mol Pathol 2012; 93: 391-8.

9. Widschwendter $M$, Jones PA. DNA methylation and breast carcinogenesis. Oncogene 2002; 21: 5462-82.

10. Zhao C, Lam EW, Sunters A, et al. Expression of estrogen receptor beta isoforms in normal breast epithelial cells and breast cancer: regulation by methylation. Oncogene 2003; 22: 7600-6.

11. Hirata S, Shoda T, Kato J, Hoshi K. The multiple untranslated first exons system of the human estrogen receptor beta (ER beta) gene. J Steroid Biochem Mol Biol 2001; 78: 33-40.

12. Skliris GP, Munot K, Bell SM, et al. Reduced expression of oestrogen receptor beta in invasive breast cancer and its re-expression using DNA methyl transferase inhibitors in a cell line model. J Pathol 2003; 201: 213-20.

13. Yap OW, Bhat G, Liu L, Tollefsbol TO. Epigenetic modifications of the estrogen receptor beta gene in epithelial ovarian cancer cells. Anticancer Res 2009; 29: 139-44.

14. Zhu X, Leav I, Leung YK, et al. Dynamic regulation of estrogen receptor-beta expression by DNA methylation during prostate cancer development and metastasis. Am J Pathol 2004; 164: 2003-12.

15. Rody A, Holtrich U, Solbach C, et al. Methylation of estrogen receptor beta promoter correlates with loss of ER-beta expression in mammary carcinoma and is an early indication marker in premalignant lesions. Endocr Relat Cancer 2005; 12: 903-16.

16. Wolff RK, Frazer KA, Jackler RK, et al. Analysis of chromosome 22 deletions in neurofibromatosis type 2-related tumors. Am J Hum Genet 1992; 51: 478-85.
17. Eads CA, Danenberg KD, Kawakami K, et al. MethyLight a high-through put assay to measure DNA methylation. Nucleic Acids Res 2000; 28: E32.

18. Liu GJ, Wu YS, Brenin D, et al. Development of a high sensitivity, nested Q-PCR assay for mouse and human aromatase. Breast Cancer Res Treat 2008; 111: 343-51.

19. Li LC, Yeh CC, Nojima D, Dahiya R. Cloning and characterization of human estrogen receptor beta promoter Biochem Biophys Res Commun 2000; 275: 682-9.

20. Suzuki F, Akahira J, Miura I, et al. Loss of estrogen receptor beta isoform expression and its correlation with aberrant DNA methylation of the 5'-untranslated region in human epithelial ovarian carcinoma. Cancer Sci 2008 99: 2365-72.

21. Ogino S, Kawasaki T, Brahmandam M, et al. Precision and performance characteristics of bisulfite conversion and real-time PCR (MethyLight) for quantitative DNA methylation analysis. J Mol Diagn 2006; 8: 209-17.

22. Widschwendter M, Siegmund KD, Muller HM, et al. Association of breast cancer DNA methylation profiles with hormone receptor status and response to tamoxifen. Cancer Res 2004; 64: 3807-13.

23. Celebiler Cavusoglu A, Sevinc Al, Saydam S, et al. Promoter methylation and expression changes of $\mathrm{CDH} 1$ and P16 genes in invasive breast cancer and adjacent normal breast tissue. Neoplasma 2010; 57: 465-472.

24. Murphy LC, Watson PH. Is oestrogen receptor-beta a predictor of endocrine therapy responsiveness in human breast cancer? Endocr Relat Cancer 2006; 13: 327-34.

25. Shaw JA, Udokang K, Mosquera JM, et al. Oestrogen receptors alpha and beta differ in normal human breast and breast carcinomas. J Pathol 2002; 198: 450-7.

26. Sowińska-Przepiera E, Syrenicz A, Friebe Z, et al. Pvull and Xbal polymorphisms of estrogen receptor-alpha and the results of estroprogestagen therapy in girls with functional hypothalamic amenorrhea - preliminary study. Arch Med Sci 2012; 8: 841-7.

27. Laird PW. The power and the promise of DNA methylation markers. Nat Rev Cancer 2003; 3: 253-66.

28. Gallegos-Arreola MP, Figuera-Villanueva LE, RamosSilva A, et al. The association between the 844ins68 polymorphism in the CBS gene and breast cancer. Arch Med Sci 2014; 10: 1214-24. 